This is an electronic reprint of the original article. This reprint may differ from the original in pagination and typographic detail.

Author(s): Brabant, Olivier; van de Ree, Maartje; Erkkilä, Jaakko

Title: $\quad$ The effect of resonance frequency breathing when used as a preparatory exercise in music psychotherapy : A single-case experimental study of a client with anxiety disorder

Year: $\quad 2017$

Version:

Please cite the original version:

Brabant, O., van de Ree, M., \& Erkkilä, J. (2017). The effect of resonance frequency breathing when used as a preparatory exercise in music psychotherapy : A singlecase experimental study of a client with anxiety disorder. The Arts in Psychotherapy, 56, 7-18. https://doi.org/10.1016/j.aip.2017.08.004

All material supplied via JYX is protected by copyright and other intellectual property rights, and duplication or sale of all or part of any of the repository collections is not permitted, except that material may be duplicated by you for your research use or educational purposes in electronic or print form. You must obtain permission for any other use. Electronic or print copies may not be offered, whether for sale or otherwise to anyone who is not an authorised user. 


\title{
The effect of resonance frequency breathing when used as a preparatory exercise in music psychotherapy: A single-case experimental study of a client with anxiety disorder
}

\author{
Olivier Brabant ${ }^{*}$, Maartje van de Ree, Jaakko Erkkilä \\ Department of Music, Art and Culture Studies, University of Jyväskylä, Finland
}

*E-mail (corresponding author): olivier.brabant@jyu.fi

\begin{abstract}
:
This study aimed at evaluating the possible benefits of starting Integrative Improvisational Music Therapy (IIMT) sessions with 10 min of Resonance Frequency Breathing (RFB), a type of slow breathing known to be beneficial for stress reduction and emotional regulation. A client diagnosed with anxiety disorder and social phobia attended 12 IIMT sessions. Using an alternating treatments design, RFB was systematically alternated with a control intervention (Vibroacoustic Therapy, VAT). Therapy processes were assessed through the Session Evaluation Questionnaire (SEQ) and the continuous measurement of Heart Rate Variability (HRV), a biomarker of autonomic nervous system response. RFB was consistently accompanied by higher HRV and followed by lower Arousal, when compared to VAT. The music psychotherapy process displayed two phases, with the first being emotionally more challenging than the second. In the first phase, the high frequency HRV component (HFnu) during music improvisations and Positivity scores were comparatively higher in sessions starting with RFB, whereas in the second phase, post-session Smoothness and Positivity were comparatively lower after RFB. The therapy outcome was positive, with marked symptom improvements. RFB appeared to have functioned as an adaptive intervention, modulating the emotional difficulty of the sessions according to the therapy phase and the client's current needs.
\end{abstract}

Keywords: music psychotherapy; improvisational music therapy; resonance frequency breathing; heart rate variability; emotional regulation; anxiety 


\section{Background}

Music psychotherapy is a form of arts therapy that uses music as a primary mode of expression within a psychotherapeutic context. Therapeutic change is achieved through a systematic process of intervention, based on musical experiences and the client-therapist relationship. Historically, music therapy has its roots in psychoanalysis and psychodynamic therapy (Bruscia, 1998). Although this legacy is still important, more recent theoretical influences include resource-oriented approaches (Rolvsjord, 2010), as well as supportive psychotherapy, which integrates psychodynamic, cognitive-behavioural, and interpersonal models (Winston, Rosenthal, \& Pinsker, 2011).

The present study focuses on a model called Integrative Improvisational Music Therapy (IIMT), originally developed at the University of Jyväskylä, Finland. The key principle of IIMT is the synergistic alternation of verbal and music-making phases, with the idea of exploiting the specific benefits offered by each of these activities. Typically, the creation of free music improvisations (together with the therapist) helps clients express their difficult emotions and inner conflicts in a novel, symbolic, and non-threatening form, whereas the verbal phases serve the purpose of reflecting upon and processing the themes that emerged during music-making (Erkkilä, Punkanen, \& Fachner, 2012). In terms of efficacy and clinical relevance, this model was used in a randomised controlled trial and shown to be more effective than standard care alone in the treatment of depression and co-morbid anxiety (Erkkilä et al., 2011).

In an attempt to develop IIMT further, we wanted to find out whether the efficacy of the model could be enhanced by the addition of a short cardiorespiratory intervention at the beginning of the sessions. Generally speaking, breathing practices are already being used for the treatment of various emotional and stress-related disorders (Brown, Gerbarg, \& Muench, 2013). It is for example well-known that autonomic arousal can be reduced with slow breathing methods such as pranayama yoga (Jerath, Edry, Barnes, \& Jerath, 2006; Pal, Velkumary, \& Madanmohan, 2004). However, these methods are still largely used on their own, although they could easily be integrated into psychotherapy, where their relaxation effects could serve as a facilitator (Gerbarg \& Brown, 2016; Pagnini, Manzoni, Castelnuovo, \& Molinari, 2013).

The intervention used in this study is known as Resonance Frequency Breathing (RFB), which is the central component of a method called heart rate variability biofeedback (Lehrer \& Gevirtz, 2014). RFB consists in slow, paced breathing at around six breaths/min, with the actual optimal speed needing to be determined on an individual basis. When people breathe at their resonance frequency, Heart Rate Variability (HRV) is maximised and heart, respiratory, and blood pressure rhythms become highly synchronised (Vaschillo, Lehrer, Rishe, \& Konstantinov, 2002). This has the immediate effect of shifting the Autonomic Nervous System (ANS) toward 
parasympathetic (rest-and-digest) dominance, leading to a state of calm alertness (Gerbarg \& Brown, 2016). The fact that RFB makes people feel both relaxed and energised distinguishes it from other relaxation techniques, where relaxation might be accompanied by increased sleepiness (Smith et al., 2000).

In terms of applications, RFB has proven to be beneficial in three broad areas. First, it can promote general well-being, by reducing stress (Sutarto, Wahab, \& Zin, 2012) and increasing people's ability for emotional regulation (McCraty \& Zayas, 2014). Second, in the area of performance enhancement, RFB has been shown to improve cognitive performance (Prinsloo et al., 2011), sport performance (Paul \& Garg, 2012), and artistic skills (Raymond, Sajid, Parkinson, \& Gruzelier, 2005). Lastly, RFB has also been successfully applied in the treatment of various physical and emotional disorders, for example asthma (Lehrer, 2012), hypertension (Lin et al., 2012), chronic muscle pain (Hallman, Olsson, von Schéele, Melin, \& Lyskov, 2011), anxiety disorder (Reiner, 2008), and depression (Karavidas et al., 2007). Thus, RFB appears to have the necessary qualities to potentially support and enhance the benefits that people already derive from music psychotherapy.

Nevertheless, RFB is still predominantly used as a stand-alone intervention, with very few attempts at combining it with other therapy methods. This is surprising, given its ease of use, inexpensiveness, and positive track record. Some exceptions do exist that involve using RFB alongside cognitive behavioural therapy (e.g. Reiner, 2008), but only as an additional, parallel intervention. Given the absence of pre-existing literature on the integration of RFB into psychotherapy, we widened our scope and considered any kind of relaxation method used as a preparatory intervention.

The few studies that we found involved hypnosis (Kirsch, Montgomery, \& Sapirstein, 1995), mindfulness-based stress reduction (Weiss, Nordlie, \& Siegel, 2005), and relaxation training (Goldfarb, Fuhr, Tsujimoto, \& Fischman, 1987). Taken collectively, they indicate that the addition of some form of relaxation resulted in better outcomes and/or shorter therapy processes, which is in itself a very encouraging finding. Unfortunately, these studies focused only on outcome measures, thus shedding little to no light on how the adjunct intervention supported the mechanisms and mediators responsible for the observed therapeutic change.

There exists, however, one recent single-case study where RFB was integrated into music psychotherapy, in an attempt to support emotional processes (Brabant, Solati, Letulè, Liarmakopoulou, \& Erkkilä, 2017). In that study, 10 min of RFB were applied at the beginning of every other session, in alternation with a control intervention (music listening). Paradoxically, RFB was consistently followed by higher stress levels during the rest of the session, because of the emergence of more negative emotions. The absence of integration problems led the authors to 
conclude that the temporary stress increases remained within the so-called therapeutic window of tolerance (Siegel, 1999). One should add that the client was a healthy client, meaning that the observed effects do not necessarily apply to a clinical population. The obtained results were in line with the outcome of a study on emotional regulation during social interaction (Butler, Wilhelm, \& Gross, 2006). The authors found that healthy women who displayed higher HRV during a slowbreathing task also experienced and expressed more negative emotions during conversations about an upsetting film.

From the point of view of psychotherapy, well-tolerated emotional activation and processing is something good and desirable, since in most theoretical orientations, working through one's issues is seen as essential for achieving a positive therapeutic outcome. However, with clients who are unable to down-regulate or whose default mode is constant hyperarousal, to further increase stress levels during therapy would obviously be counter-productive. On the contrary, such clients would rather benefit from a reduction in stress levels. This would allow them to stay (or return) inside their window of tolerance, which is a prerequisite for good client-therapist interaction and successful emotional processing (Ogden \& Minton, 2000; Siegel, 1999).

As shown in previous studies, RFB has the ability to quickly reduce stress levels by instantly shifting the ANS toward parasympathetic dominance. Therefore, we hypothesised that RFB would have two main effects when used in a psychotherapeutic context. First of all, it would open the client up and facilitate the emergence of repressed negative emotions, which might lead to a temporary increase in stress levels (Brabant et al., 2017). This effect would mainly occur in clients having a high-enough tolerance threshold and sufficient self-regulation abilities. Secondly, through its relaxation effect, RFB would also ease the emotional burden of pre-existing negative emotions, resulting in reduced stress levels. This second effect would be especially visible in clients who are in a permanent state of hyperarousal (e.g. because of post-traumatic stress disorder). Although these postulated effects work in opposite directions, by expectedly occurring in the right amount and at the appropriate moment, both would in fact support and facilitate the client's work during therapy.

In the present study, our main objective was to expand on the findings by Brabant et al. (2017) and investigate the effects of RFB on a client formally diagnosed with an emotional disorder, in order to better understand the effects that can be expected with clients presenting specific pathologies. More specifically, we sought to answer the following research questions. Does the use of RFB as a prelude to music psychotherapy have a visible and positive impact on emotional processes? Do any observable effects differ depending on the type of client?

Concretely, in the case of a client with anxiety disorder, we hypothesised that the use of RFB would primarily decrease the perceived difficulty of the sessions, and that these difficulty decreases would also be accompanied by higher HRV levels during music-making and/or verbal 
interaction. Moreover, in addition to the effects attributable to the breathing exercise, we expected the results to display a trend corresponding to the changes and improvements that naturally happen during the course of therapy. Lastly, should the client indeed experience positive changes during our study, we reasonably assumed that the effects of RFB would adapt and change accordingly, possibly even leading to increased arousal and difficulty, similarly to what Brabant et al. (2017) observed in their study with a healthy client.

\section{Method}

\section{Study design}

We performed a single-subject study with an alternating treatments design, so as to compare the effect of RFB to the effect of a control intervention. The chosen control intervention was Vibroacoustic Therapy (VAT), which consists in applying low-frequency sound waves to the client's body through speakers or transducers placed in special armchairs and mattresses. VAT is a form of receptive music therapy that can be used for example to treat hypertension, muscle spasticity, stress, and anxiety (Grocke \& Wigram, 2007). Although the efficacy of VAT still needs to be established through systematic studies (Punkanen \& Ala-Ruona, 2012), the nature of the method made it nonetheless a credible alternative to RFB, thus increasing the likelihood that the client would have an equal level of expectation towards both interventions. Furthermore, the client was unaware of our research question, and we presented both interventions as having the same purpose (relaxation).

The study consisted of 12 weekly sessions, always taking place on the same day and at the same time. Every session started with either 10 min of RFB or 10 min of VAT, followed by 45 min of improvisational music psychotherapy in the form of IIMT. The two treatment conditions were systematically alternated in consecutive order, starting with the vibroacoustic treatment in the first session. In other words, VAT was used in all the odd-numbered sessions (1, 3, 5, 7, 9, and 11), while RFB was used in all the even-numbered sessions $(2,4,6,8,10$, and 12).

The client was a 35-year-old female diagnosed with anxiety disorder and social phobia. She had undergone cognitive psychotherapy in the past, but it was the first time she tried music psychotherapy. Her formal music education consisted in some basic training in classical piano playing. As for the therapist, she was a certified music therapist holding a Bachelor's in Music Therapy from the ArtEZ School of Music, Enschede, the Netherlands. Prior to the study, she received adequate training in the principles and methods of IIMT.

It should be noted that the client was taking paroxetine, an antidepressant of the selective serotonin reuptake inhibitor (SSRI) class that is commonly prescribed for social phobia. SSRIs have 
been associated with reduced HRV levels, both in depressed and non-depressed people (O'Regan, Kenny, Cronin, Finucane, \& Kearney, 2015). However, this effect is generally considered modest, unlike other types of antidepressants (Kemp et al., 2010; Licht et al., 2008). This was anyway not a major issue, since the client served as her own control and the medication dosage remained unchanged during her participation in our study.

The music improvisations were performed either on a djembe drum (traditional WestAfrican drum) or on a malletKAT Pro, the latter being set to emulate the sound of a vibraphone. The malletKAT Pro is a Musical Instrument Digital Interface (MIDI) controller that has the same key layout as a marimba, and is played using one or two mallets. Although it is an electronic instrument, the keys of the malletKAT are pressure-sensitive, allowing for changes in dynamics and volume levels. In accordance with the IIMT model, whenever they improvised together, client and therapist were facing each other and playing the same type of instrument.

Regarding the data collection, the client was wearing a heart rate monitor in the form of a chest strap during the entire length of the sessions. The questionnaires and rating scales used in this study were administered through a desktop computer located in the music therapy room. Moreover, the sessions were filmed with non-intrusive audiovisual equipment. Written consent was obtained from the client regarding the filming of the sessions, and the fact that the collected material would be used for research purposes.

For the analysis, we chose to focus on the working phase of the therapy, and therefore excluded the first and last session, leaving us with a total of 10 sessions (five in each condition). This is sufficient with regard to the requirements defined by the What Works Clearinghouse, whereby a minimum of five observations per phase are needed to meet the standards for single-case research designs (Kratochwill et al., 2010). To evaluate the results, we mainly relied on visual data inspection. In addition, whenever a change was systematic and visible in all 10 sessions, we complemented the visual analysis with a statistical comparison of the means obtained under each condition. Since the study design consisted of the systematic alternation of two conditions, we were particularly interested in the presence of clear zigzag patterns in the data. If present, such patterns would be indicative of a possible functional relationship between the preparatory intervention and the measured variables.

\section{Interventions}

\section{Vibroacoustic Therapy (VAT)}

VAT was administered with a Next Wave Physioacoustic PRO therapy chair. Unlike the more basic MX version, the PRO version allows the use of custom-made programs, in addition to the 16 preset 
programs. The Next Wave therapy chairs received 510(k) clearance from the U.S. Food and Drug Administration (FDA) as class II medical devices (clearance number: K905256). The medical claims allowed by the FDA are tension relief, increase of blood circulation, and pain relief.

In the present study, we used a shortened version (10 $\mathrm{min})$ of a pre-existing relaxation program. Its detailed parameters can be found in Table A1. During the VAT treatment, the chair's footrest was inclined at $45^{\circ}$ upward, whereas the backrest was inclined at $45^{\circ}$ backward. While VAT was on-going, the client kept her eyes closed and the therapist sat next to her in silence.

\section{Resonance Frequency Breathing (RFB)}

In order to simplify the procedure, RFB was performed without any biofeedback instrumentation. Instead, we relied on the fact that in an adult person, the resonance frequency remains largely stable (Vaschillo, Vaschillo, \& Lehrer, 2006). We therefore determined the client's resonance frequency only once at the beginning. In subsequent sessions, we relied on that information to cue her with a visual breath pacer set at her optimal speed.

To determine the client's resonance frequency, we followed the iteration method developed by Lehrer (2007, Chapter 10). This method consists in testing six different breathing speeds (7, 6.5, $6,5.5,5$, and 4.5 breaths/min) and then identifying the speed that produces the highest HRV level. The latter is done by comparing the HRV power spectra obtained with each speed, and finding the measurement with the highest spectral peak in the vicinity of $0.1 \mathrm{~Hz}$. Indeed, when performing RFB, the entire HRV power spectrum concentrates around the frequency corresponding to the breathing speed $(6$ cycles $/ \mathrm{min}=0.1 \mathrm{~Hz})$. In the case of our client, her optimal breathing speed was exactly 6 breaths/min.

Besides the breathing speed, another factor to consider is the inhalation/exhalation (i/e) ratio. There are repeated findings indicating that longer inhalations than exhalations reduce HRV by activating the sympathetic branch of the ANS, whereas longer exhalations than inhalations increase HRV through parasympathetic activation (Porges, 2007; Strauss-Blasche et al., 2000). In a study specifically investigating the effect of the i/e ratio when breathing at 6 breaths/min, Diest et al. (2014) found that a low i/e ratio (exhalation > inhalation) induced higher levels of mindfulness, positive energy, and relaxation compared to a high i/e ratio (inhalation > exhalation). For the present study, we chose a ratio of 40/60 without pauses, meaning inhalations lasted 4 seconds and exhalations 6 seconds.

The client performed RFB while sitting on the VAT chair, with the chair turned off and the back- and footrest in an upright position. The breathing cues were given by a free app called Paced Breathing (LLC, 2015), installed on an Android tablet. We asked her to follow the visual breathing cues while holding the tablet in front of her. She was given the following breathing instructions: to 
use abdominal breathing, to breathe in through the nose and out through the mouth with pursed lips, and to keep the breathing shallow and natural so as to avoid hyperventilation. Similarly to the other intervention, when the client was performing RFB, the therapist sat next to her in silence.

\section{Process measures}

Session Evaluation Questionnaire (SEQ; Stiles, 1980; Stiles \& Snow, 1984)

The SEQ is a self-report instrument designed to evaluate the client's post-session mood, as well as the impact of each session, as perceived by the client. Its latest version consists of 21 seven-point bipolar adjective scales, regrouped to form the following independent dimensions: Positivity and Arousal for the client's affective state, Depth and Smoothness for the session evaluation. In doing so, the SEQ is following the circumplex model of emotion (Russell, 1980), whereby all emotions are mapped onto a two-dimensional space, with one dimension representing valence (positivenegative) and the other one representing arousal (activation-deactivation).

Regarding the Depth dimension, it simultaneously expresses the idea of session potency (powerful-weak) and value (valuable-worthless). As to the Smoothness dimension, it expresses whether the session was experienced as relaxed and comfortable, or rather as tense and distressing. A complete list of the adjective pairs can be found in Table A2.

The SEQ was administered at the end of each session. In addition, we also administered the mood scales (Positivity and Arousal) at the beginning of the sessions, immediately following the relaxation intervention. This enabled us to compare post-session scores to pre-session scores, and also to measure the subjective effect of the relaxation interventions on the client's affective state.

\section{Outcome measures}

Hospital Anxiety and Depression Scale (HADS; Snaith, 2003)

The HADS is a self-report instrument used to assess anxiety and depression in a non-psychiatric adult population. It consists of two sub-scales (anxiety and depression) with seven items each, scored from 0 to 3 . The HADS was administered one week before the first therapy session and then again one week after the last session.

Brief Social Phobia Scale (BSPS; Davidson et al., 1991, 1997)

The BSPS is an observer-rated instrument designed to assess the typical symptoms of social phobia. It consists of three sub-scales (fear, avoidance, and physiological arousal), and comprises a total of 18 items rated on a five-point scale. The first two sub-scales assess to what extent certain social 
situations are being feared and avoided, whereas the last sub-scale measures the intensity of physical symptoms when in social situations, such as blushing or trembling. Similarly to the HADS, the BSPS was administered one week before the beginning and one week after the end of therapy.

\section{HRV measures}

\section{Chosen indices}

In the time domain, we calculated SDNN (the standard deviation of all beat-to-beat intervals) and RMSSD (the root mean square of successive beat-to-beat interval differences). SDNN is a measure of overall HRV (i.e. how much the ANS responds), whereas RMSSD is a measure of short-term HRV (i.e. how quickly the ANS responds). We also reported average heart rate (HR). In the frequency domain, we calculated the spectral power of LF (low frequency, $0.04-0.15 \mathrm{~Hz}$ ) and HF (high frequency, $0.15-0.4 \mathrm{~Hz}$ ) using the Fast Fourier Transform algorithm (data interpolation rate: $4 \mathrm{~Hz}$ ). We also computed total power (TP), which includes all the cyclical components responsible

for HRV up to $0.4 \mathrm{~Hz}^{1}$ The results in the frequency domain were log transformed (natural $\log , \ln$ ), so as to guarantee the normality of their distribution. Furthermore, we also calculated the relative power distribution between LF and HF by converting the absolute values to normalised units (nu). ${ }^{2}$ Since their mathematical equivalence makes LFnu and HFnu redundant information (Burr, 2007), we only reported HFnu.

In terms of interpretation, HF is an indicator of vagal tone and parasympathetic activity, low $\mathrm{HF}$ corresponding to a reduced parasympathetic influence. In other words, low HF typically accompanies high physiological arousal, for instance when experiencing stress and anxiety (Cohen et al., 1998; Schwarz, Schächinger, Adler, \& Goetz, 2003). LF, however, cannot be unambiguously interpreted, as it is the combined result of sympathetic, parasympathetic, and baroreflex influences (Shaffer, McCraty, \& Zerr, 2014).

One notable fact is that all the HRV indices in a given domain have an equivalent in the other domains, to which they are highly correlated $(r>0.9)$. We know for example from existing studies that SDNN and TP tend to correlate very highly, and so do RMSSD and HF (Kleiger, Stein, \& Bigger, 2005; Shaffer et al., 2014; Task Force, 1996). Even if these correlations where

1. $\mathrm{TP}=\mathrm{VLF}+\mathrm{LF}+\mathrm{HF}$, with VLF: very low frequency $(0-0.04 \mathrm{~Hz})$, LF: low frequency $(0.04-0.15$ $\mathrm{Hz})$ and HF: high frequency $(0.15-0.4 \mathrm{~Hz})$.

2. $\mathrm{LFnu}=\mathrm{LF}\left[\mathrm{ms}^{2}\right] /\left(\mathrm{TP}\left[\mathrm{ms}^{2}\right]-\mathrm{VLF}\left[\mathrm{ms}^{2}\right]\right)$ and $\mathrm{HFnu}=\mathrm{HF}\left[\mathrm{ms}^{2}\right] /\left(\mathrm{TP}\left[\mathrm{ms}^{2}\right]-\mathrm{VLF}\left[\mathrm{ms}^{2}\right]\right)$. This is roughly equivalent to $\mathrm{LFnu}=\mathrm{LF} /(\mathrm{LF}+\mathrm{HF})$ and $\mathrm{HFnu}=\mathrm{HF} /(\mathrm{LF}+\mathrm{HF})$. 
established through 24-hour electrocardiogram recordings, we expected to find similar correspondences in the present study.

\section{Segmentation and averaging}

In typical HRV studies, all participants perform the same predefined task in the same amount of time, and researchers analyse their data in 5-minute segments, which is the standard for short-term analyses (Task Force, 1996). Such an approach is not applicable to music therapy, where moments of interest (e.g. a specific music improvisation) are unpredictable and can last anything between a few minutes to the entire length of the session. We therefore needed a methodology that would remain accurate and reliable when applied to data segments of different lengths, especially to very short ones lasting less than five minutes.

Studies investigating the reliability of HRV indices for ultra-short segments have demonstrated that SDNN and RMSSD remain reliable with segments lasting only 30 seconds (Munoz et al., 2015; Salahuddin, Cho, Jeong, \& Kim, 2007). Nevertheless, a minimum of two minutes is required for accurately capturing LF and HF, the idea being that at least 10 cycles of the lowest frequency should be present in the data when performing a power spectral analysis (Berntson et al., 1997). We therefore settled for two-minute segments, which thus became the minimum length an event needed to be considered for analysis. For any therapeutic moment lasting longer than two minutes, we averaged multiple overlapping 2-minute segments (overlap: 50\%). Indeed, the averaging of short overlapping segments is a reliable way of estimating the mean spectral values of a longer data segment (Rivecourt, Kuperus, Post, \& Mulder, 2008). The time-domain indices were calculated alongside the frequency-domain indices using the same averaging method.

\section{Data acquisition and pre-processing}

Data acquisition was performed with a Suunto Memory Belt, which is a self-contained and autonomous chest strap able to record R-R intervals without the use of an external receiver such as a wrist watch or a mobile phone. The Memory Belt has an accuracy of $1 \mathrm{~ms}$, and it can reliably substitute itself to standard electrocardiogram systems (Bouillod, Cassirame, Bousson, Jr, \& Tordi, 2015; Weippert et al., 2010). Data pre-processing and analysis was performed with version 2.2 of Kubios, a freely available HRV analysis tool (Tarvainen, Niskanen, Lipponen, Ranta-aho, \& Karjalainen, 2014).

Data pre-processing consisted of two steps. First, we removed abnormal heartbeats and noise-based artifacts with Kubios' automatic detection and correction feature. This was done by selecting the minimum sensitivity level needed for Kubios to detect all unwanted artifacts while 
leaving the rest of the data untouched. Once detected, artifacts were automatically replaced using a cubic spline interpolation method. We then detrended the data using smoothness priors $(\lambda=500)$, which rendered the heart rate signal more stationary through the removal of unwanted long-term trends (Tarvainen, Ranta-aho, \& Karjalainen, 2002). Stationarity of HRV data is a prerequisite for time- and frequency-domain analyses; in its absence, results are more likely to overestimate the contribution of the ANS' sympathetic branch (Magagnin et al., 2011).

\section{Results}

The results are presented here in the following order: immediate effects on HRV of the preparatory interventions, mood ratings, session ratings, HRV during the rest of the session (with a distinction between verbal exchange and music improvisations), and outcome measures. The detailed numerical results can be found in the Appendix, in Tables A2 and A3.It should be noted that we only included the malletKAT improvisations in our analysis of the music-making moments. The reason behind was that the malletKAT was played in every session, whereas the client used the djembe in only half the sessions, making the djembe improvisations unsuitable for comparison.

Before proceeding to the results as such, we would first like to provide a brief overview of the therapy process in terms of thematic and emotional content, as this will create a context for the interpretation of these results. After looking at the addressed topics and emotional tone of each session, it became clear that the therapy process had two distinct phases. Session 2 to 7 were characterised by the expression of mainly negative emotions (stress, nervousness, social phobia, anger), whereas session 8 to 11 were more resource-oriented, with a stronger focus on solutions and positive emotions (being social, feeling strong, being disinhibited). These two phases happened spontaneously and were not in any way planned or initiated by the therapist. Rather, all the themes that emerged throughout the therapy process were suggested by the client.

\section{HRV during the preparatory interventions}

After examining the immediate effects of the preparatory intervention on HRV measures, we found that RFB consistently increased the levels of overall HRV, as indexed by the level of total power (TP). This increase was quite substantial when compared to the levels achieved during VAT. As can be seen in Figure 1, the zigzag pattern was very pronounced, and the difference in TP after RFB ( $M$ $=8.71, S D=0.13)$ versus after VAT $(M=6.43, S D=0.22)$ was statistically highly significant, with $t(8)=20.11, p<.001$, Cohen's $d=12.62$. To give the reader a point of comparison, the average TP level for the rest of the session across all sessions was $7.33(S D=0.58)$. 


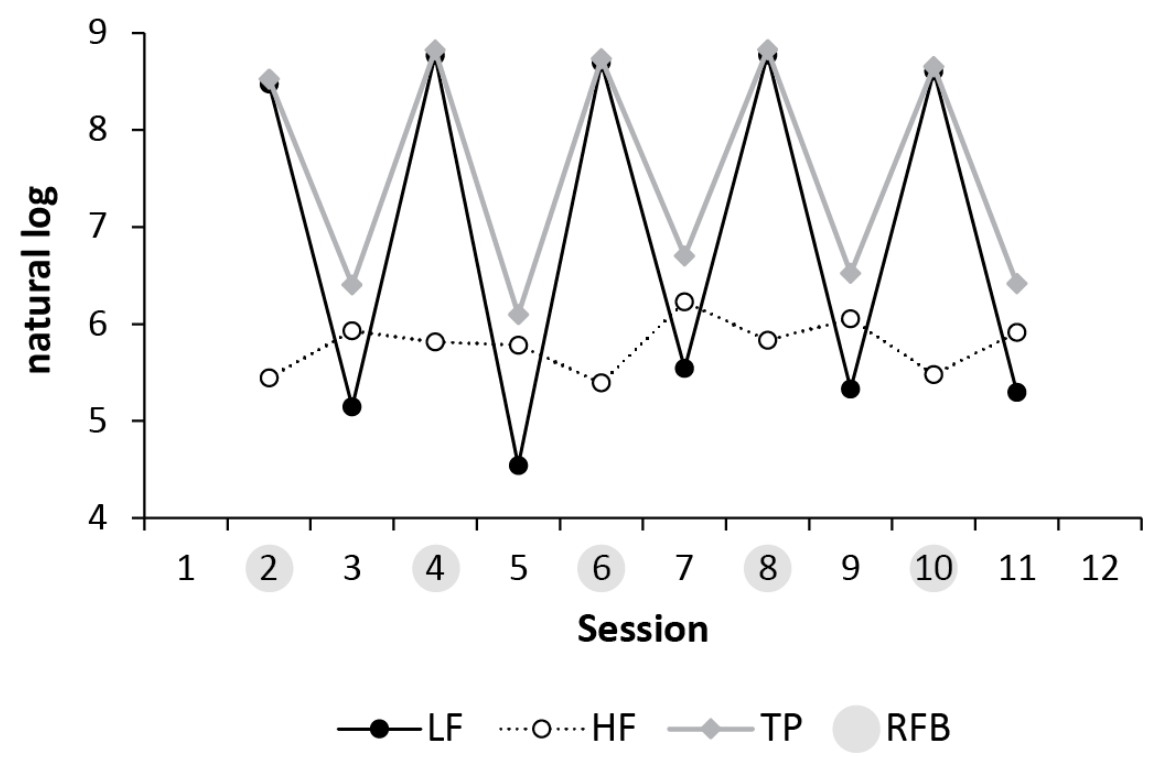

Figure 1. HRV during the preparatory intervention. LF and HF are the two main components of TP.

As expected, these high levels in TP were driven by strong increases in LF power, while HF did not display any systematic difference between interventions (see Figure 1). It is important to add the following word of caution: one should see these results as being specific to the practice of slow breathing, and not apply the usual interpretation criteria used for the frequency domain. Indeed, under normal breathing circumstances, increased relaxation would typically manifest through higher HF and not higher LF. However, as we saw in the introduction, one of the characteristics of RFB is to cause a power concentration around the resonance frequency. This frequency happens to be located in the LF band, hence the atypical HF results obtained here.

\section{Mood ratings}

The arousal levels reported by the client immediately following the preparatory intervention confirmed the existence of a link between RFB, high HRV, and increased relaxation. If we look at Figure 2, we see a clear zigzag pattern in Arousal_pre scores, with pre-session arousal levels systematically lower after RFB $(M=2.8, S D=0.24)$ than after VAT $(M=3.54, S D=0.65)$. This difference was statistically significant, with $t(8)=-2.369, p<.05$, Cohen's $d=1.51$. In other words, the results show that the breathing intervention had a stronger relaxation effect than the vibroacoustic intervention, and this difference was visible both in the physiological data and in the self-reported arousal levels. 


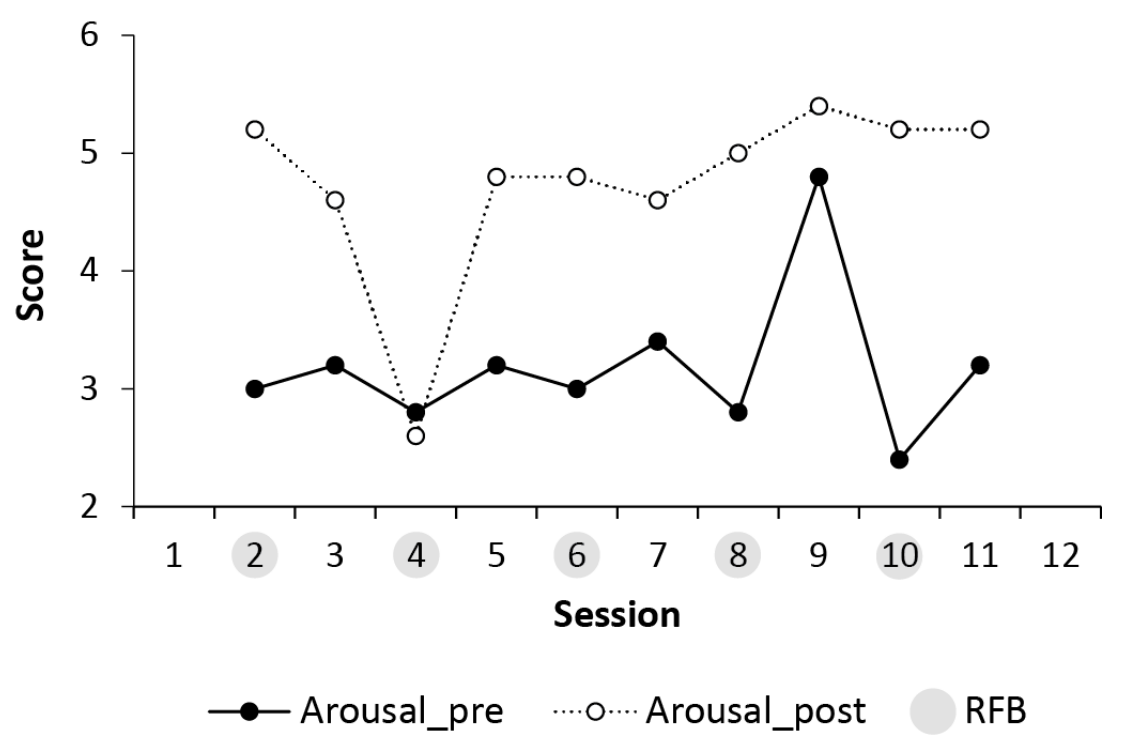

Figure 2. Client's Arousal scores on the SEQ (pre- and post-session)

Regarding the Arousal_post scores, the results indicated that the client was always more aroused at the end of the sessions, compared to the beginning of the sessions. The only exception was session 4, where the Arousal_post score was unusually low (see Figure 2). Unlike Arousal_pre, there was no zigzag pattern with Arousal_post, meaning no association was found between the preparatory interventions and the post-session arousal levels. If we ignore the two scores strongly deviating from the rest of the data (session 9 for Arousal_pre and session 4 for Arousal_post), neither measure displayed any systematic trend over time.

The interpretation of these arousal scores needs to be modulated with the results of the positivity ratings. Indeed, Figure 3 indicates that — except for sessions 9 and 11 - the client ended the sessions feeling more positive than when she started them. This means that the client would typically leave the therapy room feeling both more aroused and more positive compared to the beginning of the session. The two exceptions visible at the end of the therapy process are not caused by a sudden decrease in Positivity_post, but by ever-increasing Positivity_pre scores starting from session 7.

In terms of difference between conditions, the positivity ratings displayed clear differences in only half of the sessions, making them non-systematic. However, when they occurred, consistent differences were visible in either the first or the second therapy phase. As shown in Figure 3, there was a zigzag pattern with a slight downward trend in both Positivity_pre and _post scores from session 2 to 6 . Both positivity scores were higher in sessions starting with RFB, compared to sessions starting with VAT. Then, starting from session 7, the Positivity_post curve became almost flat, whereas Positivity_pre began an upward trend and reversed its zigzag pattern (less positive after RFB, compared to VAT). It is also worth noticing that until Positivity_pre started its upward 
trend in session 7, both positivity curves followed each other very tightly, displaying almost parallel fluctuations relative to one another.

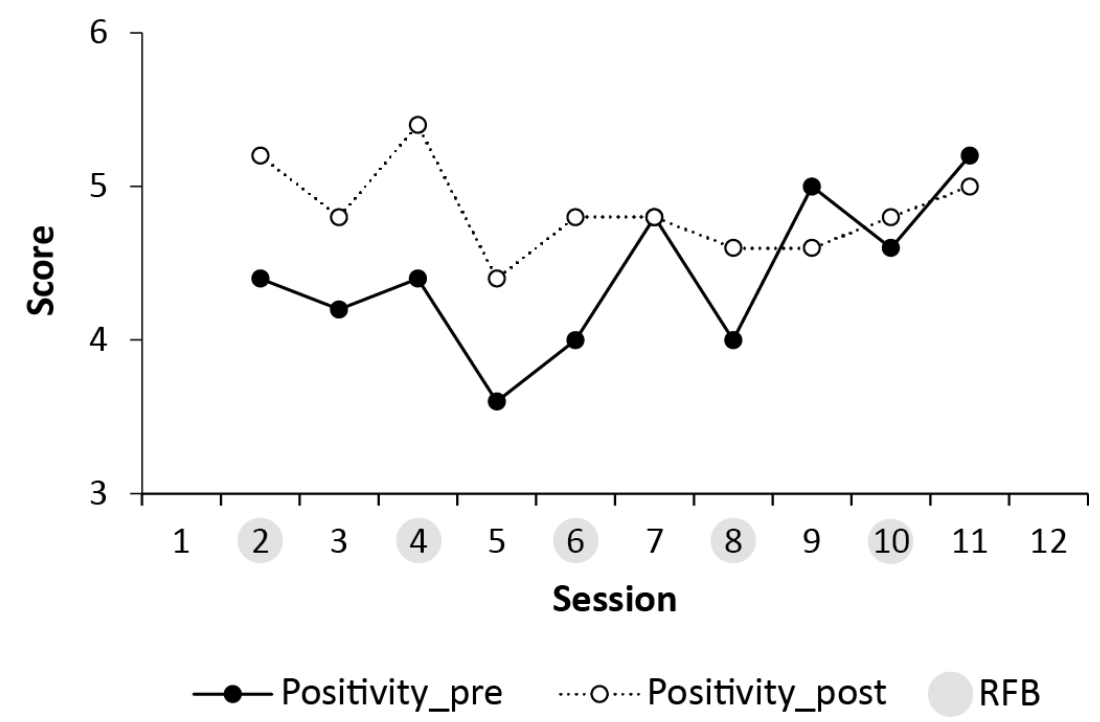

Figure 3. Client's Positivity scores on the SEQ (pre- and post-session)

\section{Session ratings}

Turning our attention now to the session ratings, no systematic pattern was visible in the Depth scores, except for a slight downward trend (see Figure 4). However, a noteworthy fact was that the session with the highest Depth score (session 4) was also the session with the highest Positivity_post score (see Figure 3), the lowest Arousal_post score (see Figure 2), and the highest level of SDNN during improvisations (see Figure 6).

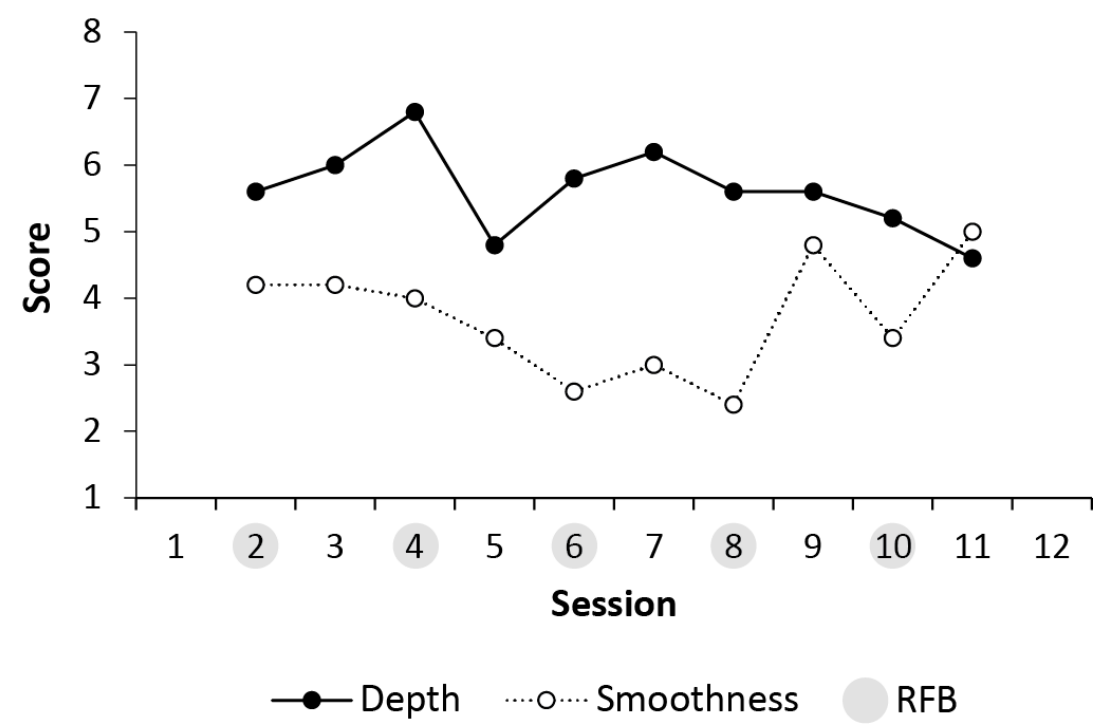

Figure 4. Client's Depth and Smoothness scores (both post-session) 
In other words, the session rated as the most powerful and valuable had the following unique characteristics: the client was the least stressed during improvisations, and she left the room feeling the calmest and the most positive, compared to all the other sessions. We know from the psychometric properties of the SEQ that Depth and Positivity usually tend to be positively correlated (Stiles et al., 1994), so this association found in session 4 between Depth and Positivity_post is in itself not surprising. However, when taken as a whole, our data did not display any significant association between these two variables $(r=.48, p=.16, n=10)$.

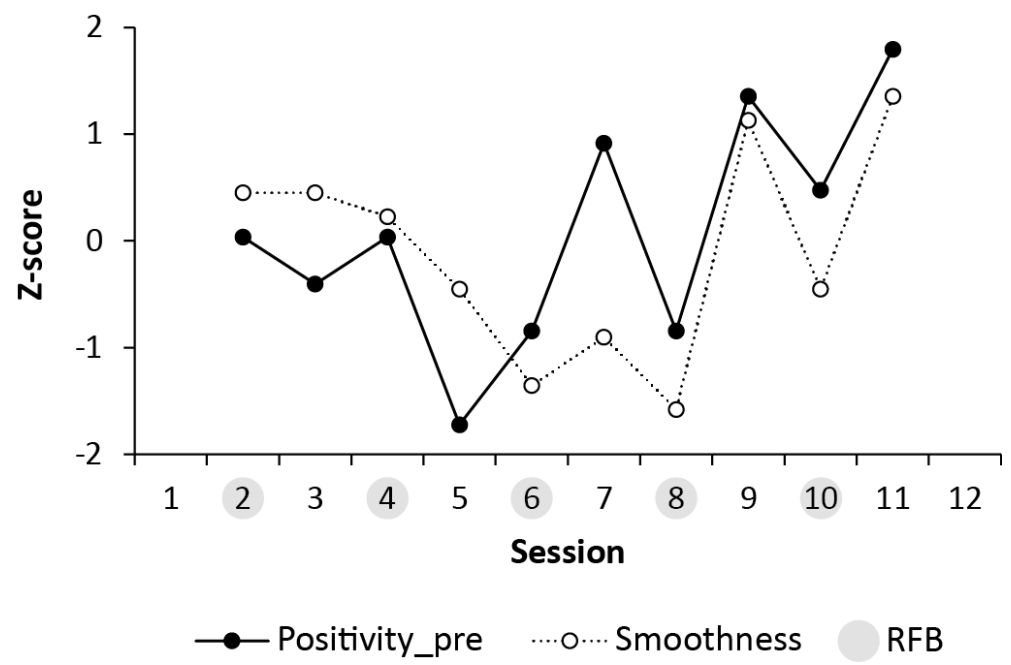

Figure 5. Comparison of Positivity_pre and Smoothness scores (after transformation into standard scores)

As to the Smoothness scores, they were characterised by an overall U-shaped trend, with a decrease until session 8 , followed by an increase until the last session. Furthermore, the upward part featured a zigzag pattern, with the two sessions starting with RFB rated lower in smoothness than the two sessions starting with VAT. One notable fact is the strong parallelism between the Smoothness and Positivity_pre scores, especially after session 7 when both curves began their zigzag pattern (see Figure 5 for a joint representation of these curves). It is also worth mentioning out that for these two scores, the beginning of the upward trend and the zigzag pattern corresponded to the second phase of the therapy process, when the sessions were more positive and resourceoriented. In other words, once this qualitative shift occurred, the client started the sessions in an increasingly positive mood, and she experienced the sessions as more and more smooth.

\section{HRV during the rest of the session}

Moving on to the HRV results, we first would like to mention a general finding regarding the difference between music-making and talking: throughout the whole therapy process, malletKAT 
improvisations were always more stressful than verbal interaction, as can be seen in Figure 6 (overall HRV was always lower during improvisations than during talking). This difference was visible in all the absolute HRV measures reported in this study (SDNN, RMSSD, LF, HF, and TP), the only exceptions being RMSSD and HF in session 4. Such a finding is very interesting, because it supports the idea that music-making and verbal interaction are really two distinct activities in terms of their emotional qualities and therapeutic functions.

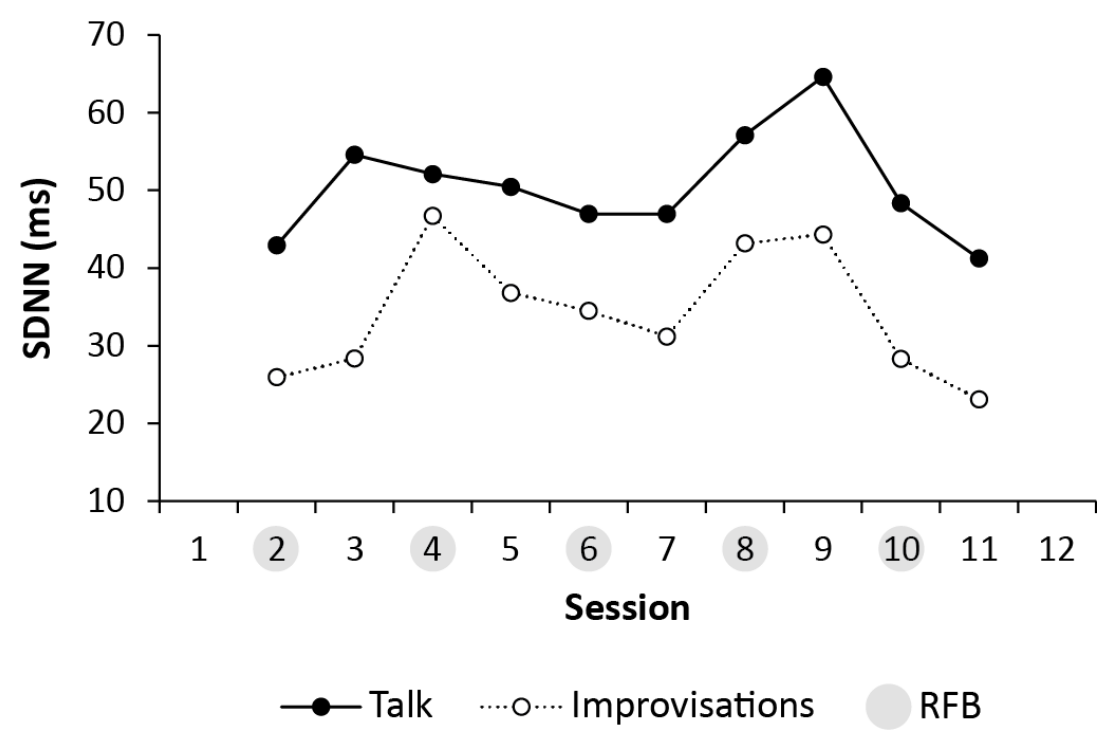

Figure 6. HRV during talking and music improvisations (SDNN)

Trend-wise, the SDNN levels for both talking and improvising did not have any clear or systematic trend, neither did they display any of the zigzag patterns identified in the other measurements. However, as can be seen in Figure 7, the plotting of HFnu during improvisations did reveal the presence of a U-shaped trend as well as a zigzag pattern. Both the downward phase and the zigzag pattern lasted from session 2 to 7 , followed by a steep and constant increase until session 11. Again, similarly to Positivity_pre and Smoothness, the turning point corresponded to the beginning of the second phase in the therapy process, when the thematic and emotional contents shifted to something more positive. As to HFnu during talking, the curve remained very flat and trendless across the 10 sessions. 


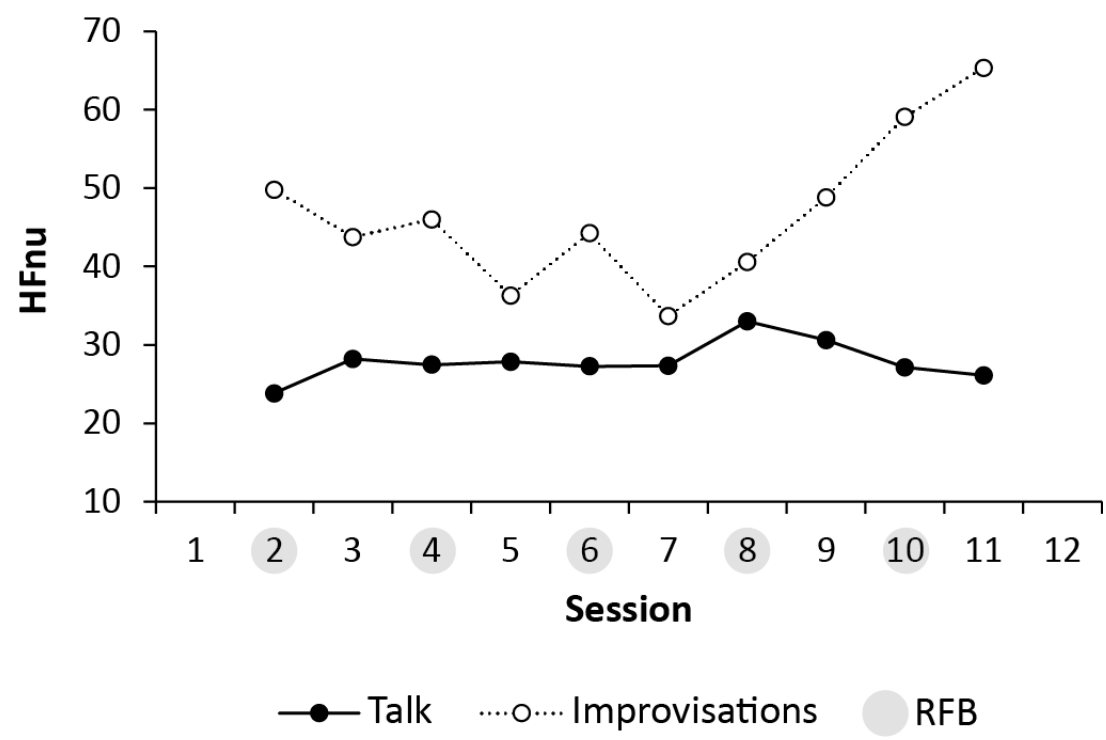

Figure 7. HRV during talking and music improvisations (HFnu)

Before finishing with the HRV results, we would like to add an important clarification about Figures 6 and 7. On the face of it, it might appear that these two figures are contradicting each other, because in Figure 6 the Improvisation curve is consistently below the Talk curve, whereas it is above the Talk curve in Figure 7. One has to keep in mind that these two figures are not directly comparable, because one is about an absolute HRV measure (SDNN), whereas the other one is about a relative HRV measure (HFnu). While it is true that both LF and HF did decrease during improvisations compared to the moments of verbal exchange (similarly to SDNN), LF always decreased more than $\mathrm{HF}$, causing the relative amount of $\mathrm{HF}$ (HFnu) to be systematically higher during improvising than during talking. In other words, the counter-intuitive results presented in Figures 6 and 7 are not spurious, but the consequence of using normalised units. This also means that Figure 7 should not be used to compare talking and improvising inside each session, but only to compare the same activity across sessions.

\section{Outcome measures}

A pre-post comparison of the outcome measures indicated that the client experienced an improvement in both her anxiety and social phobia symptoms. As shown in Table 1, her anxiety score on the HADS dropped from 12 to 8 , which corresponded to a shift from a moderate to a mild anxiety, a score of 8 being actually at the limit between mild and normal (0-7: normal, 8-10: mild, 11-14: moderate, 15-21: severe). The results of the BSPS were slightly more mixed, with a marginal increase of avoidant behaviour ( +2 points), accompanied by a reduction in fear levels (- 3 points) and an even stronger decrease in physiologic symptoms (- 5 points). All in all, based on the 
outcome measures, it appears that these 12 sessions of improvisational music therapy were beneficial to the client, which she orally confirmed during the last session ("I'm much more confident these days than I used to be", "I have really enjoyed this", "I think this has helped me very much", "It has been very relieving to show my feelings", "I got new views").

Table 1. Outcome measures

\begin{tabular}{lrrr}
\hline & Pre & Post & $\Delta$ \\
\hline HADS & & & \\
$\quad$ Anxiety $^{\mathrm{a}}$ & 12 & 8 & -4 \\
$\quad$ Depression $^{\mathrm{a}}$ & 0 & 2 & +2 \\
BSPS $^{\text {Fear }}$ & & & \\
Avoidance $^{\mathrm{b}}$ & 24 & 21 & -3 \\
Physiologic $^{\mathrm{c}}$ & 9 & 20 & +2 \\
& & 4 & -5 \\
\hline
\end{tabular}

HADS: Hospital Anxiety and Depression Scale, BSPS: Brief Social Phobia Scale

${ }^{a}$ 0-7: normal, 8-10: mild, 11-14: moderate, 15-21: severe

${ }^{b}$ Range: $0-28$

${ }^{\mathrm{c}}$ Range: $0-16$

\section{Summary}

The findings presented above were of three types. The first type was variables displaying a systematic difference between the two experimental conditions across the entire therapy process (HRV during the preparatory intervention and Arousal_pre levels). The second type was variables with non-systematic differences visible in only one half of the sessions (HFnu during improvisations, Smoothness, and Positivity_pre and_post). Lastly, we also had variables that did not display any difference between conditions (Arousal_post, Depth, all absolute HRV indices during the rest of the session, and HFnu during talking). For an overview of the findings, we refer the reader to Table 2 . 
Table 2. Overview of the findings in process measures

\begin{tabular}{|c|c|c|}
\hline \multicolumn{3}{|c|}{ Systematic difference between conditions } \\
\hline & & Observed difference \\
\hline \multicolumn{2}{|c|}{ HRV during preparatory intervention ${ }^{a}$} & higher during RFB \\
\hline \multicolumn{2}{|l|}{ Arousal_pre } & lower right after RFB \\
\hline \multicolumn{3}{|c|}{ Non-systematic difference during at least half of the therapy } \\
\hline & \multicolumn{2}{|c|}{ Type of change } \\
\hline & $\begin{array}{l}\text { Higher in the more difficult } \\
\left(1^{\text {st }}\right) \text { phase }\end{array}$ & $\begin{array}{l}\text { Lower in the more easy } \\
\left(2^{\text {nd }}\right) \text { phase }\end{array}$ \\
\hline HFnu (impro) & $\checkmark$ & - \\
\hline Smoothness & - & $\checkmark$ \\
\hline Positivity_pre & $\checkmark$ & $\checkmark$ \\
\hline \multirow[t]{2}{*}{ Positivity_post } & $\checkmark$ & - \\
\hline & difference, neither systema & ic nor partial \\
\hline \multicolumn{3}{|l|}{ Arousal_post } \\
\hline \multicolumn{3}{|l|}{ Depth } \\
\hline \multicolumn{3}{|c|}{ Absolute HRV indices } \\
\hline \multicolumn{3}{|l|}{ HFnu (talk) } \\
\hline
\end{tabular}

${ }^{\mathrm{a} A l l} \mathrm{HRV}$ indices (absolute and relative), except HF

It is worth noticing that the variables with systematic differences were all related to the execution of the preparatory intervention, whereas the variables with partial or non-systematic differences all had to do with the rest of the session (i.e. the music psychotherapy part as such). Another relevant finding was that when variables displayed a consistent difference in only part of the sessions, this part was either the first (more difficult) phase or the second (easier) phase of the therapy process. Moreover, three of the latter variables (HFnu during improvisations, Smoothness, and Positivity_pre) displayed a U-shaped trend (easy-difficult-easy), with the turning point (session 8) corresponding to the passage from the first to the second therapy phase.

Interestingly enough, in each of these two phases, the direction of the observed change was consistent between the variables (see Table 2). In the first phase, although they displayed a downward trend, HFnu (impro), Positivity_pre, and Positivity_post were all comparatively higher after RFB. In other words, while things were getting progressively more difficult (until session 7), certain aspects of the client's experience were nonetheless easier in sessions starting with RFB. Conversely, once things started to become easier, Smoothness and Positivity_pre began an upward trend while remaining comparatively lower in sessions starting with RFB. Taken together, these results point to the existence of two different effects of RFB that were opposite in nature and seemed to depend on the therapy phase. 


\section{Discussion}

The goal of this study was to investigate to what extent emotion-based processes could be facilitated and supported during Integrative Improvisational Music Therapy (IIMT) by starting the sessions with a tailor-made breathing exercise called Resonance Frequency Breathing (RFB). The second objective was to better understand the specific ways in which RFB might affect clients with emotional disorders.

When looking at the findings as a whole, certain interesting patterns emerged among the positive results. One pattern was that for variables displaying consistent differences in only one therapy phase, the direction of the change (increase/decrease) and the moment of its appearance (first phase/second phase) were in line with our initial hypothesis regarding the effects of RFB. Indeed, we postulated that RFB would have a double function: it would serve as an emotional regulator and reduce arousal levels in case of hyperarousal, while also being a catalyst of difficult emotions, thus temporarily increasing stress levels. The latter, however, would only happen if people are able to cope with these emerging negative emotions.

Should our hypothesis be correct, we would logically expect the effects of RFB to vary not only from person to person, but also within a person, depending on the current phase of the therapy process. As we saw in our results, this was indeed the case: in the phase dominated by negative emotions, certain aspects became easier after RFB (higher HFnu during improvisations and higher pre/post Positivity), whereas in the second, smoother phase, other aspects became more difficult in sessions starting with RFB (lower Smoothness and Positivity_pre). It should be noted that the presence of a U-shaped course — such as the one we found in three of the variables - is typical for therapy methods involving emotional exploration and expression. Moreover, this pattern (easydifficult-easy) is usually linked with good therapeutic outcomes (Watson \& Bedard, 2006), as was indeed the case in the present study.

Generally speaking, due to the nature of psychotherapy, the unavoidable presence of cumulative changes from session to session means that sequential observations in a single subject are bound to be autocorrelated (i.e. non-independent). This is considered an issue in Single-Subject Experimental Designs (SSEDs), especially when performing statistical analyses (Borckardt et al., 2008). However, one advantage of psychotherapy research is that we can predict the patterns that characterise successful and unsuccessful therapy courses, such as the U-shaped trend mentioned above. It means that these known, non-random patterns can easily be identified and factored in when performing the data analysis, thus greatly minimising the problem of autocorrelation. Naturally, how easy it is to distinguish between expected patterns and treatment effects also depends on the chosen study design. Had we opted for an AB design instead of an alternating 
treatments design (e.g. six sessions starting with VAT followed by six sessions starting with RFB), it would have been impossible to tell the intervention effects from the natural course of therapy.

Obviously, in terms of internal validity and confidence in the cause-effect relationship, the present study does not allow us to make any claim about a causal link between RFB and changes observed in only part of the therapy process. However, the results are internally consistent and support our theory that the effects of RFB are adaptive, meaning that they follow the client's current emotional needs. Moreover, this theory is corroborated by the findings of Brabant et al. (2017), who used a similar set-up, but with a healthy client and a different control intervention (listening to relaxation music instead of VAT). In that study, the client experienced more stress after RFB, in accordance with the hypothesis that someone with a higher tolerance threshold would see the emergence of difficult emotions that were normally not expressed. In sum, given the evidence available so far, the hypothetical modus operandi of RFB could be summarised as follows: with $\mathrm{RFB}$, the difficult becomes easier, and the easy becomes more difficult.

Another noteworthy pattern was that variables presenting a systematic difference throughout the entire therapy process were all directly connected to the practice of RFB. Two important conclusions can be drawn from this. Firstly, the immediate effects of RFB on HRV appear to be quite strong and reliable, since all (bar one) HRV indices were systematically and markedly higher during RFB, compared to VAT. However, the fact that a clear and consistent differential effect was found for RFB while it was being performed is not surprising. Indeed, to our knowledge, its ability to instantly and dramatically maximise HRV is unrivalled. Therefore, we did not expect VAT to even come close in terms of HRV increase.

Consequently, a more important question would be, how did RFB and VAT compare in terms of achieved relaxation? Indeed, although perceived stress levels usually correlate with objective stress levels as measured through HRV, this has not been necessarily true in every study (Hynynen, Konttinen, Kinnunen, Kyröläinen, \& Rusko, 2011; Riese, Van Doornen, Houtman, \& De Geus, 2004). Therefore, one should not exclude the possibility of sometimes finding a disconnect between the two. This was, however, not the case in our results. According to the pre-session arousal scores, the client was systematically calmer immediately after RFB, which means that RFB had a stronger relaxation effect than VAT. Thus, our second conclusion is that RFB was superior to VAT both in terms of HRV increase and relaxation, at least in the 10-minute format used in the present study. As a side note, when VAT is being used as the main intervention, the typical length of a VAT session is 20 to 40 min (Grocke \& Wigram, 2007; Lehikoinen, 1997), so the results reported here are not necessarily representative of the effects that can be achieved with the vibroacoustic method. 
Naturally, the really interesting results are not the ones involving the immediate effects of RFB, but its effects on the rest of the session. One of the merits of the present study is to shed some light on the nature of these effects and the differences that can be expected depending on the client population. However, two aspects that remain elusive are the intensity and actual duration of these effects. In other words, does RFB have an impact on the entire session or only a part of it? Furthermore, are the effects constant while they last or do they progressively fade?

The current study was not designed to address these issues, and existing research only focused on short-term effects visible in HRV (Karavidas et al., 2007; Zucker, Samuelson, Muench, Greenberg, \& Gevirtz, 2009). In both studies, SDNN was higher in the 5-minute resting period immediately following RFB, compared to the resting period preceding RFB. While they demonstrate the existence of a carry-over effect (at least on HRV), the time period under consideration ( $5 \mathrm{~min}$ ) is too short to allow any extrapolation to an entire therapy session, whose typical length is $45-60 \mathrm{~min}$. Anyhow, these findings are not directly relevant for therapists, whose clients did not come to rest but to be actively involved in therapeutic work. This distinction is important, as our findings show that during therapy, RFB might not always lead to increased relaxation, but also to higher stress levels. In other words, when RFB is applied as a preparatory intervention within psychotherapy, increased HRV (i.e. less stress) is not a reliable indicator of persisting carry-over effects.

At this point, given the state of our knowledge, we can only formulate a theory regarding the intensity and duration of any carry-over effect produced by RFB. The following theory is based on the common properties of IIMT and RFB, and thus only applies to therapy methods involving symbolic and spontaneous expression through an art form. We would like to propose that the intrinsic qualities of music-making, being similar to the ones of RFB, support and sustain the emotional opening process that is initiated by RFB. Indeed, one of the key features of music improvisations is to help clients with the expression of difficult emotions, by offering them a nonverbal form of communication (MacDonald \& Wilson, 2014). This is similar to the postulated effects of RFB, which are to facilitate the emergence of negative emotions, while at the same time making this confrontation bearable. Consequently, it is quite possible that RFB may be impacting the entire session, through the creation of a self-sustaining feedback loop between RFB and the music-making activities.

Regarding the use of HRV measurements as a source of objective physiological data within psychotherapy research, the present study illustrates how relative HRV indices are an important complement to absolute indices. Indeed, we found a systematic difference in absolute indices only when the measured effect was strong and obvious, meaning during the breathing exercise itself. As soon as the effects became smaller and more subtle (i.e. during the rest of the session), the only 
HRV index displaying a difference between conditions was HFnu, which is a relative index. It is worth mentioning that the same phenomenon was reported by Brabant et al. (2017), who only found statistical differences in HFnu and LFnu, and none in the absolute HRV indices (breathing intervention aside).

One likely explanation is that absolute HRV indices typically display strong intra-individual variations from one recording to the next, an expected minimum of $10-30 \%$ being the norm (Pinna, 2007; Sandercock, Bromley, \& Brodie, 2005). Consequently, natural variations in HRV might mask the effect of an intervention, if that effect is smaller than these natural variations. However, changes in absolute HRV that are masked by natural variations might remain visible in LFnu and HFnu, because these normalised indices minimise the effect of changes in total HRV spectral power. As a result, when used in repeatability studies, LFnu and HFnu typically have much smaller coefficients of variation compared to their non-normalised counterparts (Burr, 2007).

Because our study only involved a single subject, it is of course impossible to generalise the findings to a larger population. In order to do so, RFB would need to be tested in a randomised controlled trial comparing a treatment group to a control group. Such a design would also make it possible to properly assess the impact of RFB on outcome measures, which is something our current study did not allow either. However, it is important to stress that SSEDs play a valuable role within the framework of evidence-based practice. Because of their inherent flexibility and focus on causal relationships, SSEDs are ideal for developing new therapeutic methods and evaluating their efficacy prior to their application in parallel group designs (Byiers, Reichle, \& Symons, 2012).

We are aware that for this new therapeutic approach to easily translate to clinical practice, the HRV methodology that we used in conjunction with RFB would have to be simplified. One readily available solution would be to substitute smartphone technology for the more professional heart rate monitors and electrocardiogram systems. Indeed, it has nowadays become possible to measure heart rate quite accurately by placing a finger on the phone's camera (Coppetti et al., 2017). Although not necessarily suitable for research purposes, the smartphone option constitutes a viable and convenient alternative for therapists who wish to use RFB with their clients.

To conclude, the results presented here are promising enough to warrant further studies, in the form of SSEDs as well as larger between-group comparisons. Should the supporting effects of RFB be confirmed and their clinical relevance established, therapists might have a new tool at their disposal to cost-effectively, safely, and easily enhance the effectiveness of therapy, which would have the added benefit of potentially reducing healthcare costs through shorter therapy processes. 


\section{Acknowledgement}

This work was supported by a personal grant from the Jenny and Antti Wihuri Foundation (to the first author).

\section{Appendix}

Table A1. Settings of the Physioacoustic chair

\begin{tabular}{cccccccccccc}
\hline Step & Length $^{\text {a }}$ & Freq. $^{\text {b }}$ & Scan $^{\mathrm{c}}$ & Speed $^{\text {d }}$ & Cycles $^{\mathrm{e}}$ & Action $^{\text {f }}$ & Strength $^{\mathrm{g}}$ & Neck $^{\mathrm{h}}$ & Back $^{\mathrm{h}}$ & Thighs $^{\mathrm{h}}$ & Legs $^{\mathrm{h}}$ \\
\hline 1 & 2 & 40.06 & 0 & 0 & 0 & 1 & 3 & 3 & 4 & 6 & 6 \\
2 & 2 & 39.06 & 0 & 0 & 0 & 1 & 3 & 3 & 4 & 6 & 6 \\
3 & 2 & 34.27 & 0 & 0 & 0 & 1 & 3 & 3 & 4 & 6 & 6 \\
4 & 2 & 44.64 & 0 & 0 & 0 & 1 & 3 & 3 & 4 & 6 & 6 \\
5 & 2 & 40.06 & 0 & 0 & 0 & 1 & 3 & 3 & 4 & 6 & 6 \\
\hline
\end{tabular}

${ }^{\mathrm{a}}$ minutes

${ }^{\mathrm{b}}$ Hertz

${ }^{c}$ Fluctuation range around the central frequency ( $0=$ no fluctuation)

${ }^{\mathrm{d}}$ Speed of the fluctuation around the central frequency (range: 0 - 99)

e How fast the wave moves up and down the chair (range: 0 - 99)

${ }^{f}$ Direction of the wave $(1=$ from the legs to the head)

g Overall strength (range : 0 - 9)

${ }^{\mathrm{h}}$ Individual strength of various parts of the chair (range : 0 - 9)

Table A2. Results of the Session Evaluation Questionnaire (SEQ)

\begin{tabular}{|c|c|c|c|c|c|c|c|c|c|c|c|c|}
\hline & \multicolumn{10}{|c|}{ Session } & \multirow[b]{2}{*}{$M$} & \multirow[b]{2}{*}{$S D$} \\
\hline & 2 & 3 & 4 & 5 & 6 & 7 & 8 & 9 & 10 & 11 & & \\
\hline \multicolumn{13}{|l|}{ Mood evaluation } \\
\hline Positivity_pre & 4.4 & 4.2 & 4.4 & 3.6 & 4 & 4.8 & 4 & 5 & 4.6 & 5.2 & 4.42 & 0.49 \\
\hline Positivity_post & 5.2 & 4.8 & 5.4 & 4.4 & 4.8 & 4.8 & 4.6 & 4.6 & 4.8 & 5 & 4.84 & 0.30 \\
\hline Arousal_pre & 3 & 3.2 & 2.8 & 3.2 & 3 & 3.4 & 2.8 & 4.8 & 2.4 & 3.2 & 3.18 & 0.64 \\
\hline Arousal_post & 5.2 & 4.6 & 2.6 & 4.8 & 4.8 & 4.6 & 5 & 5.4 & 5.2 & 5.2 & 4.74 & 0.80 \\
\hline \multicolumn{13}{|c|}{ Session evaluation } \\
\hline Depth & 5.6 & 6 & 6.8 & 4.8 & 5.8 & 6.2 & 5.6 & 5.6 & 5.2 & 4.6 & 5.62 & 0.65 \\
\hline Smoothness & 4.2 & 4.2 & 4 & 3.4 & 2.6 & 3 & 2.4 & 4.8 & 3.4 & 5 & 3.70 & 0.89 \\
\hline
\end{tabular}

Adjective pairs that constitute the four scales of the SEQ:

Positivity: happy-sad, angry-pleased, uncertain-definite, confident-afraid, friendly-unfriendly

Arousal: wakeful-sleepy, moving-still, calm-excited, slow-fast, energetic-peaceful, quiet-aroused

Depth: valuable-worthless, shallow-deep, full-empty, weak-powerful, special-ordinary

Smoothness: difficult-easy, relaxed-tense, unpleasant-pleasant, rough-smooth, comfortable-uncomfortable 
Table A3. Heart Rate Variability (HRV) measures

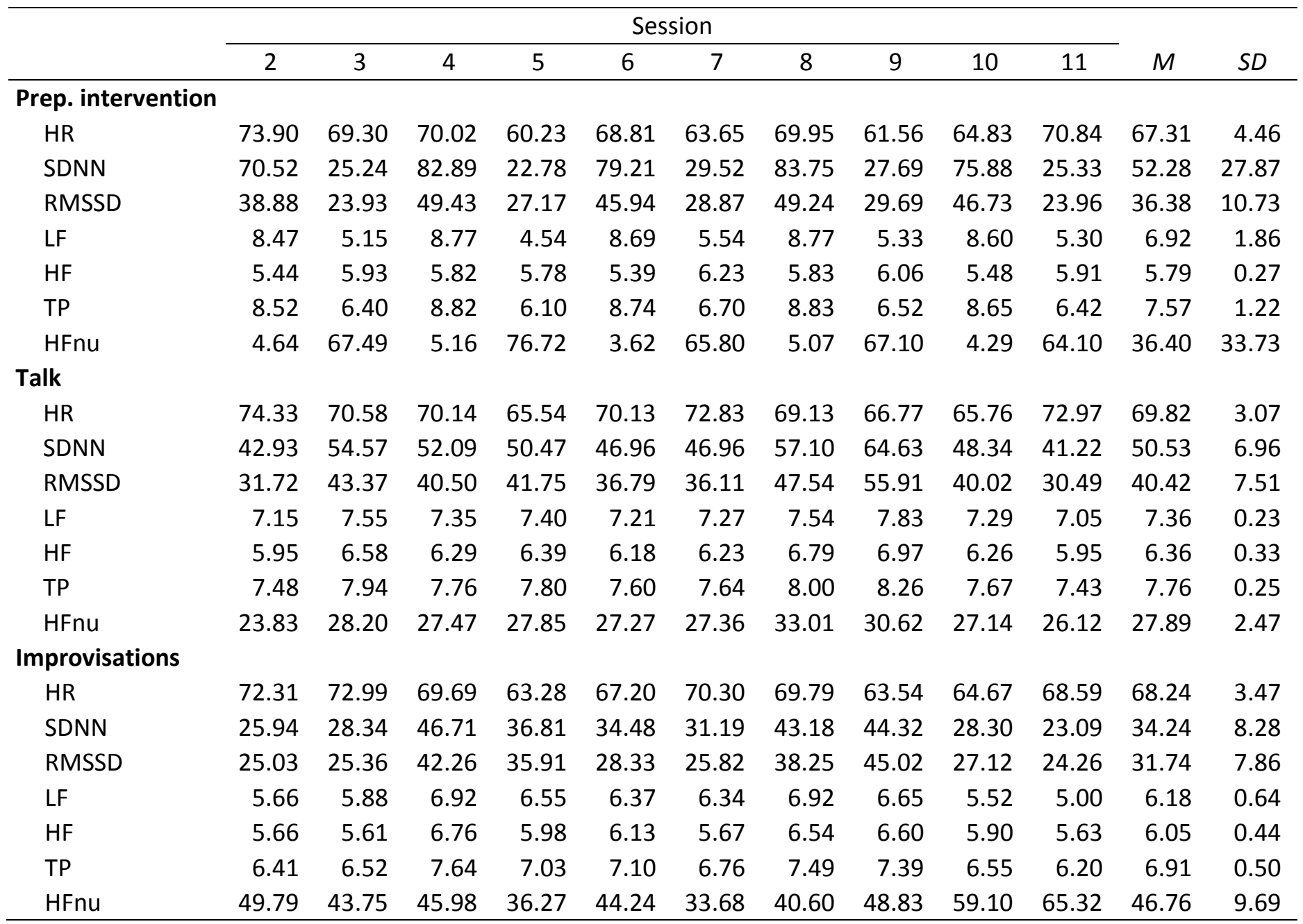

HR: heart rate (beats/min), SDNN: standard deviation of all beat-to-beat (NN) intervals (ms), RMSSD: root mean square of successive beat-to-beat interval differences (ms), LF: low frequency (natural log), HF: high frequency (natural log), TP: total power (natural log), LFnu: low frequency (normalised units), HFnu: high frequency (normalised units).

All values are session means, obtained through the averaging of multiple overlapping 2-min segments (50\% overlap). 


\section{References}

Berntson, G. G., Thomas, J., Eckberg, D. L., Grossman, P., Kaufmann, P. G., Malik, M., ... van der Molen, M. W. (1997). Heart rate variability: Origins, methods, and interpretive caveats. Psychophysiology, 34(6), 623-648. https://doi.org/10.1111/j.1469-8986.1997.tb02140.x

Borckardt, J. J., Nash, M. R., Murphy, M. D., Moore, M., Shaw, D., \& O’Neil, P. (2008). Clinical practice as natural laboratory for psychotherapy research: a guide to case-based time-series analysis. The American Psychologist, 63(2), 77-95. https://doi.org/10.1037/0003066X.63.2.77

Bouillod, A., Cassirame, J., Bousson, J. M., Jr, Y. S., \& Tordi, N. (2015). Accuracy of the Suunto system for heart rate variability analysis during a tilt-test. Brazilian Journal of Kinanthropometry and Human Performance, 17(4), 409-417. https://doi.org/10.5007/19800037.2015v17n4p409

Brabant, O., Solati, S., Letulè, N., Liarmakopoulou, O., \& Erkkilä, J. (2017). Favouring emotional processing in improvisational music therapy through resonance frequency breathing: a single-case experimental study with a healthy client. Nordic Journal of Music Therapy, 26(5), 453-472. https://doi.org/10.1080/08098131.2016.1277253

Brown, R. P., Gerbarg, P. L., \& Muench, F. (2013). Breathing practices for treatment of psychiatric and stress-related medical conditions. Psychiatric Clinics of North America, 36(1), 121-140. https://doi.org/10.1016/j.psc.2013.01.001

Bruscia, K. E. (Ed.). (1998). The dynamics of music psychotherapy. Gilsum, NH: Barcelona Publishers.

Burr, R. L. (2007). Interpretation of normalized spectral heart rate variability indices in sleep research: A critical review. Sleep, 30(7), 913-919.

Butler, E. A., Wilhelm, F. H., \& Gross, J. J. (2006). Respiratory sinus arrhythmia, emotion, and emotion regulation during social interaction. Psychophysiology, 43(6), 612-622. https://doi.org/10.1111/j.1469-8986.2006.00467.x

Byiers, B. J., Reichle, J., \& Symons, F. J. (2012). Single-subject experimental design for evidencebased practice. American Journal of Speech-Language Pathology, 21(4), 397-414. https://doi.org/10.1044/1058-0360(2012/11-0036)

Cohen, H., Kotler, M., Matar, M. A., Kaplan, Z., Loewenthal, U., Miodownik, H., \& Cassuto, Y. (1998). Analysis of heart rate variability in posttraumatic stress disorder patients in response to a trauma-related reminder. Biological Psychiatry, 44(10), 1054-1059. https://doi.org/10.1016/S0006-3223(97)00475-7

Coppetti, T., Brauchlin, A., Müggler, S., Attinger-Toller, A., Templin, C., Schönrath, F., ... Wyss, C. A. (2017). Accuracy of smartphone apps for heart rate measurement. European Journal of Preventive Cardiology, 24(12), 1287-1293. https://doi.org/10.1177/2047487317702044

Davidson, J. R., Miner, C. M., De Veaugh-Geiss, J., Tupler, L. A., Colket, J. T., \& Potts, N. L. (1997). The Brief Social Phobia Scale: A psychometric evaluation. Psychological Medicine, 27(01), 161-166.

Davidson, J. R., Potts, N. L., Richichi, E. A., Ford, S. M., Krishnan, K. R., Smith, R. D., \& Wilson, W. (1991). The Brief Social Phobia Scale. Journal of Clinical Psychiatry, 52(Suppl), 48-51.

Diest, I. V., Verstappen, K., Aubert, A. E., Widjaja, D., Vansteenwegen, D., \& Vlemincx, E. (2014). Inhalation/exhalation ratio modulates the effect of slow breathing on heart rate 
variability and relaxation. Applied Psychophysiology and Biofeedback, 39(3-4), 171-180. https://doi.org/10.1007/s10484-014-9253-X

Erkkilä, J., Punkanen, M., \& Fachner, J. (2012). Perspectives on creativity in improvisational, psychodynamic music therapy. In D. Hargreaves, D. Miell, \& R. MacDonald (Eds.), Musical imaginations: Multidisciplinary perspectives on creativity, performance and perception (pp. 414-428). Oxford: Oxford University Press.

Erkkilä, J., Punkanen, M., Fachner, J., Ala-Ruona, E., Pöntiö, I., Tervaniemi, M., ... Gold, C. (2011). Individual music therapy for depression: Randomised controlled trial. The British Journal of Psychiatry, 199(2), 132-139. https://doi.org/10.1192/bjp.bp.110.085431

Gerbarg, P. L., \& Brown, R. P. (2016). Breathing practices for mental health and aging. In H. Lavretsky, M. Sajatovic, \& C. Reynolds III (Eds.), Complementary and integrative therapies for mental health and aging (1 edition, pp. 239-255). New York, NY: Oxford University Press.

Goldfarb, L. A., Fuhr, R., Tsujimoto, R. N., \& Fischman, S. E. (1987). Systematic desensitization and relaxation as adjuncts in the treatment of anorexia nervosa: A preliminary study. Psychological Reports, 60(2), 511-518. https://doi.org/10.2466/pr0.1987.60.2.511

Grocke, D., \& Wigram, T. (2007). Vibroacoustic therapy in receptive music therapy. In Receptive methods in music therapy: Techniques and clinical applications for music therapy clinicians, educators and students (1st ed., pp. 214-235). London: Jessica Kingsley Publishers.

Hallman, D. M., Olsson, E. M. G., von Schéele, B., Melin, L., \& Lyskov, E. (2011). Effects of heart rate variability biofeedback in subjects with stress-related chronic neck pain: A pilot study. Applied Psychophysiology \& Biofeedback, 36(2), 71-80.

Hynynen, E., Konttinen, N., Kinnunen, U., Kyröläinen, H., \& Rusko, H. (2011). The incidence of stress symptoms and heart rate variability during sleep and orthostatic test. European Journal of Applied Physiology, 111(5), 733-741. https://doi.org/10.1007/s00421-010-1698$\mathrm{X}$

Jerath, R., Edry, J. W., Barnes, V. A., \& Jerath, V. (2006). Physiology of long pranayamic breathing: Neural respiratory elements may provide a mechanism that explains how slow deep breathing shifts the autonomic nervous system. Medical Hypotheses, 67(3), 566-571. https://doi.org/10.1016/j.mehy.2006.02.042

Karavidas, M. K., Lehrer, P., Vaschillo, E., Vaschillo, B., Marin, H., Buyske, S., ... Hassett, A. (2007). Preliminary results of an open label study of heart rate variability biofeedback for the treatment of major depression. Applied Psychophysiology and Biofeedback, 32(1), 1930. https://doi.org/10.1007/s10484-006-9029-z

Kemp, A. H., Quintana, D. S., Gray, M. A., Felmingham, K. L., Brown, K., \& Gatt, J. M. (2010). Impact of depression and antidepressant treatment on heart rate variability: A review and meta-analysis. Biological Psychiatry, 67(11), 1067-1074. https://doi.org/10.1016/j.biopsych.2009.12.012

Kirsch, I., Montgomery, G., \& Sapirstein, G. (1995). Hypnosis as an adjunct to cognitivebehavioral psychotherapy: a meta-analysis. Journal of Consulting and Clinical Psychology, 63(2), 214-220.

Kleiger, R. E., Stein, P. K., \& Bigger, J. T. (2005). Heart rate variability: Measurement and clinical utility. Annals of Noninvasive Electrocardiology, 10(1), 88-101. https://doi.org/10.1111/j.1542-474X.2005.10101.x 
Kratochwill, T. R., Hitchcock, J., Horner, R. H., Levin, J. R., Odom, S. L., Rindskopf, D. M., \& Shadish, W. R. (2010). Single-case designs technical documentation. Retrieved from https://ies.ed.gov/ncee/wwc/Document/229

Lehikoinen, P. (1997). The physioacoustic method. In T. Wigram \& C. Dileo (Eds.), Music, vibration, and health (pp. 209-215). Cherry Hill, NJ: Jeffrey Books.

Lehrer, P., \& Gevirtz, R. (2014). Heart rate variability biofeedback: How and why does it work? Frontiers in Psychology, 5. https://doi.org/10.3389/fpsyg.2014.00756

Lehrer, P. (2007). Biofeedback training to increase heart rate variability. In P. Lehrer, R. Woolfolk, \& W. Sime (Eds.), Principles and practice of stress management (3rd ed., pp. 227-248). New York, London: Guilford Press.

Lehrer, P. (2012). Biofeedback therapy for asthma. In R. D. Anbar (Ed.), Functional Respiratory Disorders (pp. 179-205). New York, NY: Humana Press. https://doi.org/10.1007/978-161779-857-3_10

Licht, C. M., de Geus, E. J. C., Zitman, F. G., Hoogendijk, W. J. G., van Dyck, R., \& Penninx, B. W. J. H. (2008). Association between major depressive disorder and heart rate variability in The Netherlands Study of Depression and Anxiety (NESDA). Archives of General Psychiatry, 65(12), 1358-1367. https://doi.org/10.1001/archpsyc.65.12.1358

Lin, G., Xiang, Q., Fu, X., Wang, S., Wang, S., Chen, S., ... Wang, T. (2012). Heart rate variability biofeedback decreases blood pressure in prehypertensive subjects by improving autonomic function and baroreflex. The Journal of Alternative and Complementary Medicine, 18(2), 143-152. https://doi.org/10.1089/acm.2010.0607

LLC, T. (2015). Paced Breathing (Version 2.1) [Android 2.3 or later]. Trex LLC. Retrieved from https://play.google.com/store/apps/details?id=com.apps.paced.breathing

MacDonald, R. A., \& Wilson, G. B. (2014). Musical improvisation and health: A review. Psychology of Well-Being, 4(1), 20. https://doi.org/10.1186/s13612-014-0020-9

Magagnin, V., Bassani, T., Bari, V., Turiel, M., Maestri, R., Pinna, G. D., \& Porta, A. (2011). Nonstationarities significantly distort short-term spectral, symbolic and entropy heart rate variability indices. Physiological Measurement, 32(11), 1775. https://doi.org/10.1088/0967$3334 / 32 / 11 / \mathrm{S} 05$

McCraty, R., \& Zayas, M. A. (2014). Cardiac coherence, self-regulation, autonomic stability, and psychosocial well-being. Frontiers in Psychology, 5. https://doi.org/10.3389/fpsyg.2014.01090

Munoz, M. L., Roon, A. van, Riese, H., Thio, C., Oostenbroek, E., Westrik, I., ... Snieder, H. (2015). Validity of (ultra-)short recordings for heart rate variability measurements. PLOS ONE, 10(9), e0138921. https://doi.org/10.1371/journal.pone.0138921

Ogden, P., \& Minton, K. (2000). Sensorimotor psychotherapy: One method for processing traumatic memory. Traumatology, 6(3), 149-173. https://doi.org/10.1177/153476560000600302

O’Regan, C., Kenny, R. A., Cronin, H., Finucane, C., \& Kearney, P. M. (2015). Antidepressants strongly influence the relationship between depression and heart rate variability: Findings from The Irish Longitudinal Study on Ageing (TILDA). Psychological Medicine, 45(3), 623-636. https://doi.org/10.1017/S0033291714001767

Pagnini, F., Manzoni, G. M., Castelnuovo, G., \& Molinari, E. (2013). A brief literature review about relaxation therapy and anxiety. Body, Movement and Dance in Psychotherapy, 8(2), 71-81. https://doi.org/10.1080/17432979.2012.750248 
Pal, G. K., Velkumary, S., \& Madanmohan. (2004). Effect of short-term practice of breathing exercises on autonomic functions in normal human volunteers. The Indian Journal of Medical Research, 120(2), 115-121.

Paul, M., \& Garg, K. (2012). The effect of heart rate variability biofeedback on performance psychology of basketball players. Applied Psychophysiology and Biofeedback, 37(2), 131144. https://doi.org/10.1007/s10484-012-9185-2

Pinna, G. D. (2007). Heart rate variability measures: A fresh look at reliability. Clinical Science, (3), 131. https://doi.org/10.1042/CS20070055

Porges, S. W. (2007). The polyvagal perspective. Biological Psychology, 74(2), 116-143. https://doi.org/10.1016/j.biopsycho.2006.06.009

Prinsloo, G. E., Rauch, H. G. L., Lambert, M. I., Muench, F., Noakes, T. D., \& Derman, W. E. (2011). The effect of short duration heart rate variability (HRV) biofeedback on cognitive performance during laboratory induced cognitive stress. Applied Cognitive Psychology, 25(5), 792-801. https://doi.org/10.1002/acp.1750

Punkanen, M., \& Ala-Ruona, E. (2012). Contemporary vibroacoustic therapy: Perspectives on clinical practice, research, and training. Music and Medicine, 4(3), 128-135.

Raymond, J., Sajid, I., Parkinson, L. A., \& Gruzelier, J. H. (2005). Biofeedback and dance performance: A preliminary investigation. Applied Psychophysiology and Biofeedback, 30(1), 65-73. https://doi.org/10.1007/s10484-005-2175-x

Reiner, R. (2008). Integrating a portable biofeedback device into clinical practice for patients with anxiety disorders: Results of a pilot study. Applied Psychophysiology and Biofeedback, 33(1), 55-61. https://doi.org/10.1007/s10484-007-9046-6

Riese, H., Van Doornen, L. J., Houtman, I. L., \& De Geus, E. J. (2004). Job strain in relation to ambulatory blood pressure, heart rate, and heart rate variability among female nurses. Scandinavian Journal of Work, Environment \& Health, 30(6), 477-485. https://doi.org/10.5271/sjweh.837

Rivecourt, M. D., Kuperus, M. N., Post, W. J., \& Mulder, L. J. M. (2008). Cardiovascular and eye activity measures as indices for momentary changes in mental effort during simulated flight. Ergonomics, 51(9), 1295-1319. https://doi.org/10.1080/00140130802120267

Rolvsjord, R. (2010). Resource-oriented music therapy in mental health care. Gilsum, NH: Barcelona Publishers.

Russell, J. A. (1980). A circumplex model of affect. Journal of Personality and Social Psychology, 39(6), 1161-1178. https://doi.org/10.1037/h0077714

Salahuddin, L., Cho, J., Jeong, M. G., \& Kim, D. (2007). Ultra short term analysis of heart rate variability for monitoring mental stress in mobile settings. In 29th Annual International Conference of the IEEE Engineering in Medicine and Biology Society, 2007. EMBS 2007 (pp. 4656-4659). https://doi.org/10.1109/IEMBS.2007.4353378

Sandercock, G. R. H., Bromley, P. D., \& Brodie, D. A. (2005). The reliability of short-term measurements of heart rate variability. International Journal of Cardiology, 103(3), 238247. https://doi.org/10.1016/j.ijcard.2004.09.013

Schwarz, A. M., Schächinger, H., Adler, R. H., \& Goetz, S. M. (2003). Hopelessness is associated with decreased heart rate variability during championship chess games. Psychosomatic Medicine, 65(4), 658-661. https://doi.org/10.1097/01.PSY.0000075975.90979.2A

Shaffer, F., McCraty, R., \& Zerr, C. L. (2014). A healthy heart is not a metronome: An integrative review of the heart's anatomy and heart rate variability. Frontiers in Psychology, 5. https://doi.org/10.3389/fpsyg.2014.01040 
Siegel, D. J. (1999). The developing mind: How relationships and the brain interact to shape who we are. New York, NY: Guilford Press.

Smith, J. C., Wedell, A. B., Kolotylo, C. J., Lewis, J. E., Byers, K. Y., \& Segin, C. M. (2000). ABC relaxation theory and the factor structure of relaxation states, recalled relaxation activities, dispositions, and motivations. Psychological Reports, 86(3 Pt 2), 1201-1208. https://doi.org/10.2466/pr0.2000.86.3c.1201

Snaith, R. P. (2003). The Hospital Anxiety and Depression Scale. Health and Quality of Life Outcomes, 1, 29. https://doi.org/10.1186/1477-7525-1-29

Stiles, W. B. (1980). Measurement of the impact of psychotherapy sessions. Journal of Consulting and Clinical Psychology, 48(2), 176-185. https://doi.org/10.1037/0022-006X.48.2.176

Stiles, W. B., Reynolds, S., Hardy, G. E., Rees, A., Barkham, M., \& Shapiro, D. A. (1994). Evaluation and description of psychotherapy sessions by clients using the Session Evaluation Questionnaire and the Session Impacts Scale. Journal of Counseling Psychology, 41(2), 175-185. https://doi.org/http://dx.doi.org/10.1037/0022-0167.41.2.175

Stiles, W. B., \& Snow, J. S. (1984). Dimensions of psychotherapy session impact across sessions and across clients. British Journal of Clinical Psychology, 23(1), 59-63. https://doi.org/10.1111/j.2044-8260.1984.tb00627.x

Strauss-Blasche, G., Moser, M., Voica, M., McLeod, D., Klammer, N., \& Marktl, W. (2000). Relative timing of inspiration and expiration affects respiratory sinus arrhythmia. Clinical and Experimental Pharmacology and Physiology, 27(8), 601-606. https://doi.org/10.1046/j.1440-1681.2000.03306.x

Sutarto, A. P., Wahab, M. N. A., \& Zin, N. M. (2012). Resonant breathing biofeedback training for stress reduction among manufacturing operators. International Journal of Occupational Safety and Ergonomics, 18(4), 549-561. https://doi.org/10.1080/10803548.2012.11076959

Tarvainen, M. P., Niskanen, J.-P., Lipponen, J. A., Ranta-aho, P. O., \& Karjalainen, P. A. (2014). Kubios HRV - Heart rate variability analysis software. Computer Methods and Programs in Biomedicine, 113(1), 210-220. https://doi.org/10.1016/j.cmpb.2013.07.024

Tarvainen, M. P., Ranta-aho, P. O., \& Karjalainen, P. A. (2002). An advanced detrending method with application to HRV analysis. IEEE Transactions on Biomedical Engineering, 49(2), 172-175. https://doi.org/10.1109/10.979357

Task Force. (1996). Heart rate variability standards of measurement, physiological interpretation, and clinical use. Circulation, 93(5), 1043-1065. https://doi.org/10.1161/01.CIR.93.5.1043

Vaschillo, E., Lehrer, P., Rishe, N., \& Konstantinov, M. (2002). Heart rate variability biofeedback as a method for assessing baroreflex function: A preliminary study of resonance in the cardiovascular system. Applied Psychophysiology and Biofeedback, 27(1), 1-27. https://doi.org/10.1023/A:1014587304314

Vaschillo, E., Vaschillo, B., \& Lehrer, P. (2006). Characteristics of resonance in heart rate variability stimulated by biofeedback. Applied Psychophysiology and Biofeedback, 31(2), 129-142. https://doi.org/10.1007/s10484-006-9009-3

Watson, J. C., \& Bedard, D. L. (2006). Clients' emotional processing in psychotherapy: A comparison between cognitive-behavioral and process-experiential therapies. Journal of Consulting and Clinical Psychology, 74(1), 152-159. https://doi.org/10.1037/0022006X.74.1.152

Weippert, M., Kumar, M., Kreuzfeld, S., Arndt, D., Rieger, A., \& Stoll, R. (2010). Comparison of three mobile devices for measuring R-R intervals and heart rate variability: Polar S810i, 
Suunto t6 and an ambulatory ECG system. European Journal of Applied Physiology, 109(4), 779-786. https://doi.org/10.1007/s00421-010-1415-9

Weiss, M., Nordlie, J. W., \& Siegel, E. P. (2005). Mindfulness-Based Stress Reduction as an adjunct to outpatient psychotherapy. Psychotherapy and Psychosomatics, 74(2), 108-112. https://doi.org/10.1159/000083169

Winston, A., Rosenthal, R. N., \& Pinsker, H. (2011). Learning supportive psychotherapy: An illustrated guide core competencies in psychotherapy (1 Pap/DVD edition). Washington, DC: American Psychiatric Publishing Inc.

Zucker, T. L., Samuelson, K. W., Muench, F., Greenberg, M. A., \& Gevirtz, R. N. (2009). The effects of respiratory sinus arrhythmia biofeedback on heart rate variability and posttraumatic stress disorder symptoms: A pilot study. Applied Psychophysiology and Biofeedback, 34(2), 135-143. https://doi.org/10.1007/s10484-009-9085-2 